Acta Technologica Agriculturae 1

Nitra, Slovaca Universitas Agriculturae Nitriae, 2015, pp. 10-13

\title{
STUDY ON CORRELATION OF DATA FROM YIELD MONITORING SYSTEM AND HAND SAMPLES
}

\author{
Martin INGELI*, Jana GALAMBOŠOVÁ, Miroslav MACÁK, Vladimír RATAJ \\ Slovak University of Agriculture in Nitra, Slovak Republic
}

\begin{abstract}
One of the basic tools used in precision agriculture technology is yield monitoring and mapping. Yield maps are used to monitor the efficiency of applied inputs, to assess the variability of field and have potential to be used in farm records and farm management software. The paper deals with comparison of yield maps with information on yield obtained from hand sampling. Analyses are based on five-year data from one field with spring barley, oil seed rape, winter wheat and maize crop rotation. Results show that the correlation coefficient across the time period reached a value of $0.89(p<0.05)$, which means that the yield maps show the yield trend of the field. However, looking at the data in more detail and comparing the pairs of data for selected (discrete) monitoring points, the error of estimation was calculated. This error showed that the yield monitor underestimated or overestimated the yield in average by $25 \%$. Therefore, the data cannot be used to evaluate the absolute yield at selected place of the field.
\end{abstract}

Keywords: precision agriculture, winter wheat, spring barley, maize, oil seed rape

The first and most used technology within precision agriculture is yield monitoring and mapping. The role of yield mapping is important and can be seen in two applications (Adamchuk et al., 2004):

- monitoring and mapping the initial variability of the field;

- monitoring and mapping the results of the precision management of the field.

As Blackmoore (2003) presented, one of the first developments was to put a GPS on a combine harvester and produce a new generation of yield maps. This development was technology led, and to some respects it still is today.

Yield monitoring can be defined as a continual recording of actual yield, moisture and sometimes other parameters together with the corresponding geographical position (Galambošová and Godwin, 2012). Each sensor has to be calibrated to convert the signal into physical parameters. The volume sensors have to usually incorporate grain density (hectolitre weight). Others use the weight of the full tank as a calibration factor. As moisture can vary across the field, it is also recorded and yield is calculated for standard reference moisture. Pre-processing of data obtained by yield monitoring systems is needed. The solution was proposed by Moore (1997) and recently by Ingeli et al. (2013).

When using the yield monitoring data for farm records in terms of absolute values and for the field variability assessment, accuracy of data is important. The error obtained for total yield was $-3.78 \%$ and $-3.25 \%$ for two experimental fields using the Claydon Yield-O-Meter with Claas combine harvester (Stott et al., 1993). Auernhammer et al. (1993) compared the performance of the Massey Ferguson flow control system with the Claas Yield-O-Meter. They concluded that the overall performance of both yield sensors was very similar. Burks et al. (2002) reported that the GreenStar yield sensor predicted accumulated mass with less than a $4 \%$ error (under dynamically varying step and ramp flow rates) within normal operating conditions of $4.2-16.9 \mathrm{~kg} \mathrm{~s}^{-1}\left(10-40 \mathrm{bu} \mathrm{min}^{-1}\right)$ and predicted flow at upper limits of $20 \mathrm{~kg} \mathrm{~s}^{-1}$ with a $7.3 \%$ error.

Presented paper deals with the correlation analyses of yield monitoring system data and hand samples data. The aim of the paper was to evaluate the correlation between the hand samples and the yield monitor data obtained during the commercial use of combine harvester.

\section{Material and methods}

The study compares two sources of yield data, the hand samples data as an independent variable and the yield monitoring data as a dependent variable. All data were obtained at one field (16 ha) at University Farm in Kolíñany. The following crops were grown at the experimental field: 2009 - spring barley, 2010 - oil seed rape, 2011 - winter wheat, 2012 - spring barley, 2013 - maize. In each year the crop was grown with standard technological practices. Data were obtained from 18 monitoring points spread across the field.

\section{Hand sampling data}

Before the harvest, the yield samples were taken at the monitoring points. The crop was hand harvested from $1 \mathrm{~m}^{2}$ with three replications at each monitoring point when growing small grain crops. When growing maize, $13.3 \mathrm{~m}$ long sections within crop rows spaced at $0.75 \mathrm{~m}$ apart to represent $10 \mathrm{~m}^{2}$. The samples were processed, and dry yield was calculated according to Eq. (1) for the standard reference 
moisture $14 \%$ for cereals and $8 \%$ for oil seed rape:

$$
\begin{gathered}
\text { Yield }_{\text {compensed }}=\text { Yield }_{\text {recorded }} \times \\
\times \frac{100-\text { Moisture }_{\text {recorded }}}{100-\text { Moisture }_{\text {reference }}}
\end{gathered}
$$

\section{Yield monitoring data}

The optical yield monitoring system was used in this study. All settings respected the producer recommendations. The calibration procedure was applied before the experimental field was harvested. Data were exported into a .shp file and displayed in ArcGIS (ESRI, 2014). The representative value for each monitoring point was obtained as an average of three nearest records in the row crossing the monitoring point.

The basic statistics, test of normality and correlation analyses were performed using Statistica (StatSoft Inc., 2013).

\section{Results and discussion}

Data from different seasons were analysed separately. The basic statistics of data is given in Table 1. First of all, the

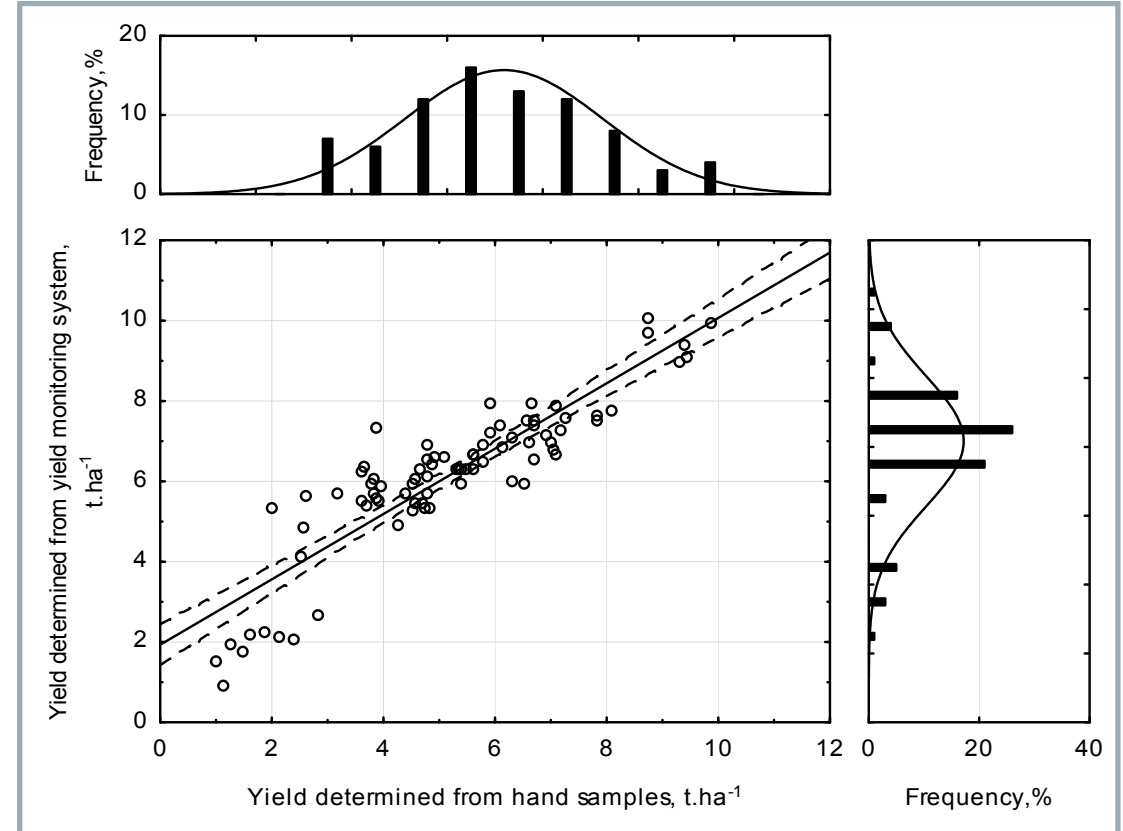

Figure 1 Correlation analyses of yield determined from hand samples and yield monitoring system

normality of data was tested. Due to small number of elements in samples, the Shapiro-Wilk test was applied. Based on the results given (Table 2), it can be concluded that all datasets are normally distributed $(W>p)$.
Correlation analyses were performed, considering the hand samples as an independent variable and information from the yield monitor as a dependent variable. The results are given in Table 3, regression analyses were added. Figure 1 shows

Table 1 Descriptive statistics of data from the yield monitoring system (referred to as A) and hand samples (referred to as B), the results of the pair $t$-test at $p<0.05$ are indicated with small letters $\left({ }^{a},{ }^{b}\right)$, comparing the $A$ and $B$ data for different years separately

\begin{tabular}{|l||c|c|c|c|c|c|c|c|c|c|}
\hline \multirow{2}{*}{ Statistics/ parameter } & \multicolumn{2}{|c|}{2009} & \multicolumn{2}{c|}{2010} & \multicolumn{2}{c|}{2011} & \multicolumn{2}{c|}{2012} & \multicolumn{2}{c|}{2013} \\
\cline { 2 - 11 } & A & B & A & B & A & B & A & B & A & B \\
\hline \hline Mean in t.ha-1 $^{-1}$ & $6.28^{\mathrm{a}}$ & $5.13^{\mathrm{b}}$ & $1.92^{\mathrm{a}}$ & $1.74^{\mathrm{a}}$ & $8.13^{\mathrm{a}}$ & $7.75^{\mathrm{b}}$ & $5.97^{\mathrm{a}}$ & $4.58^{\mathrm{b}}$ & $6.23^{\mathrm{a}}$ & $4.85^{\mathrm{b}}$ \\
\hline Standard deviation in t.ha-1 $^{-1}$ & 0.59 & 0.74 & 0.50 & 0.61 & 1.08 & 1.25 & 0.72 & 1.06 & 0.91 & 1.71 \\
\hline Minimum in t.ha $^{-1}$ & 4.94 & 3.67 & 0.91 & 1.00 & 6.70 & 5.93 & 4.86 & 2.56 & 4.11 & 7.96 \\
\hline Maximum in t.ha-1 $^{-1}$ & 7.95 & 6.54 & 2.67 & 2.81 & 10.05 & 9.85 & 7.51 & 6.68 & 1.98 & 7.17 \\
\hline Coefficient of variability in \% & 9.35 & 14.48 & 25.85 & 34.78 & 13.27 & 16.10 & 12.08 & 23.01 & 14.69 & 35.19 \\
\hline
\end{tabular}

Table 2 Results from the Shapiro-Wilk test at $\alpha=0.05$ for data from the yield monitoring system (referred to as A) and hand samples (referred to as B)

\begin{tabular}{|l||c|c|c|c|c|c|c|c|c|c|}
\hline \multirow{2}{*}{$\begin{array}{l}\text { Statistical } \\
\text { parameter }\end{array}$} & \multicolumn{2}{|c|}{2009} & \multicolumn{2}{c|}{2010} & \multicolumn{2}{c|}{$\mathbf{2 0 1 1} 2012$} & \multicolumn{2}{c|}{2013} \\
\cline { 2 - 12 } & A & B & A & B & A & B & A & B & A & B \\
\hline \hline Parameter W & 0.88 & 0.98 & 0.94 & 0.95 & 0.84 & 0.93 & 0.95 & 0.98 & 0.97 & 0.93 \\
\hline p crit & 0.02 & 0.96 & 0.59 & 0.74 & 0.01 & 0.22 & 0.39 & 0.92 & 0.79 & 0.18 \\
\hline
\end{tabular}

Table 3 Correlation coefficient and regression coefficient of hand samples data as an independent variable and yield monitoring data as a dependent variable ( ${ }^{*}$ significant at $p<0.05$ )

\begin{tabular}{|l||c|c|c|c|c|c|}
\hline Statistical parameter/Year & $\mathbf{2 0 0 9}$ & $\mathbf{2 0 1 0}$ & $\mathbf{2 0 1 1}$ & $\mathbf{2 0 1 2}$ & $\mathbf{2 0 1 3}$ & $\mathbf{5}$ years average \\
\hline \hline Correlation coefficient & 0.31 & $0.78^{*}$ & $0.88^{*}$ & $0.78^{*}$ & $0.73^{*}$ & $0.89^{*}$ \\
\hline Regression coefficient & 0.09 & $0.61^{*}$ & $0.77^{*}$ & $0.60^{*}$ & $0.53^{*}$ & $0.79^{*}$ \\
\hline
\end{tabular}


Table 4 Basic statistics of error in yield determination, calculated as a difference of yield monitoring data and hand samples data in \%

\begin{tabular}{|l|c|}
\hline Parameter & Error in \% \\
\hline \hline Mean & 25.38 \\
\hline Standard deviation & 30.59 \\
\hline Minimum & -20.79 \\
\hline Maximum & 170.46 \\
\hline
\end{tabular}

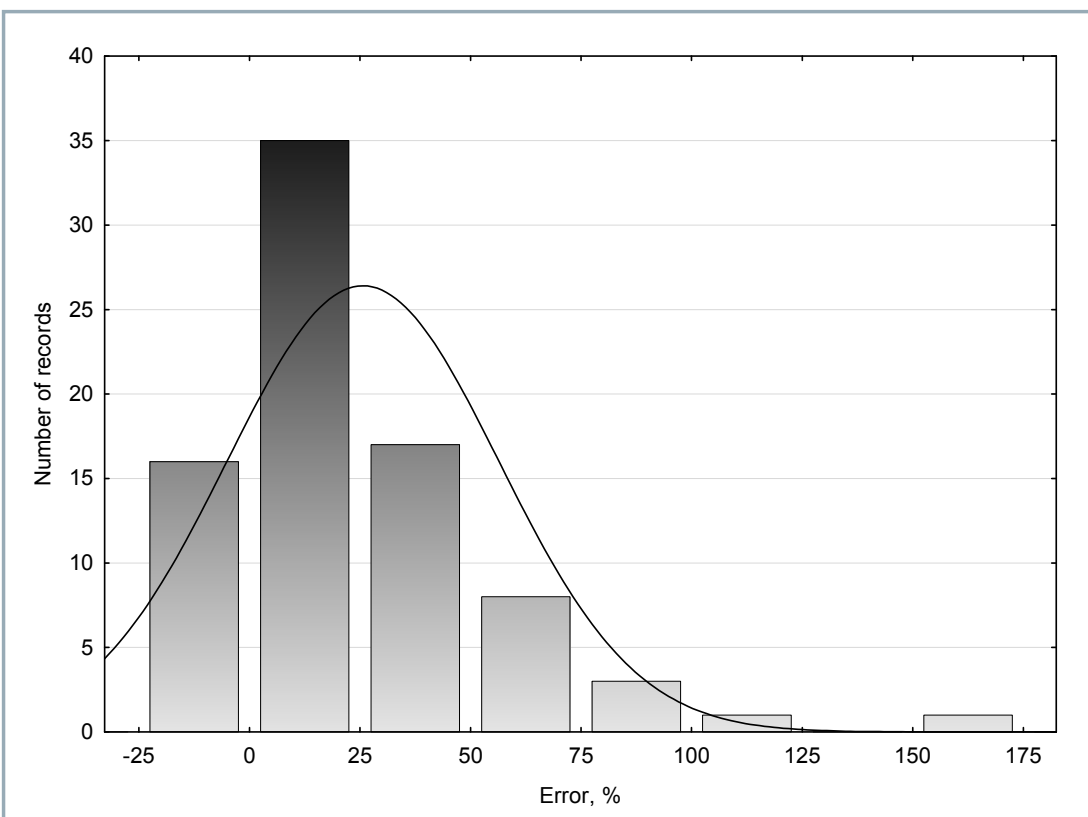

Figure 2 Histogram of percent errors calculated as a difference of yield monitoring data and hand samples

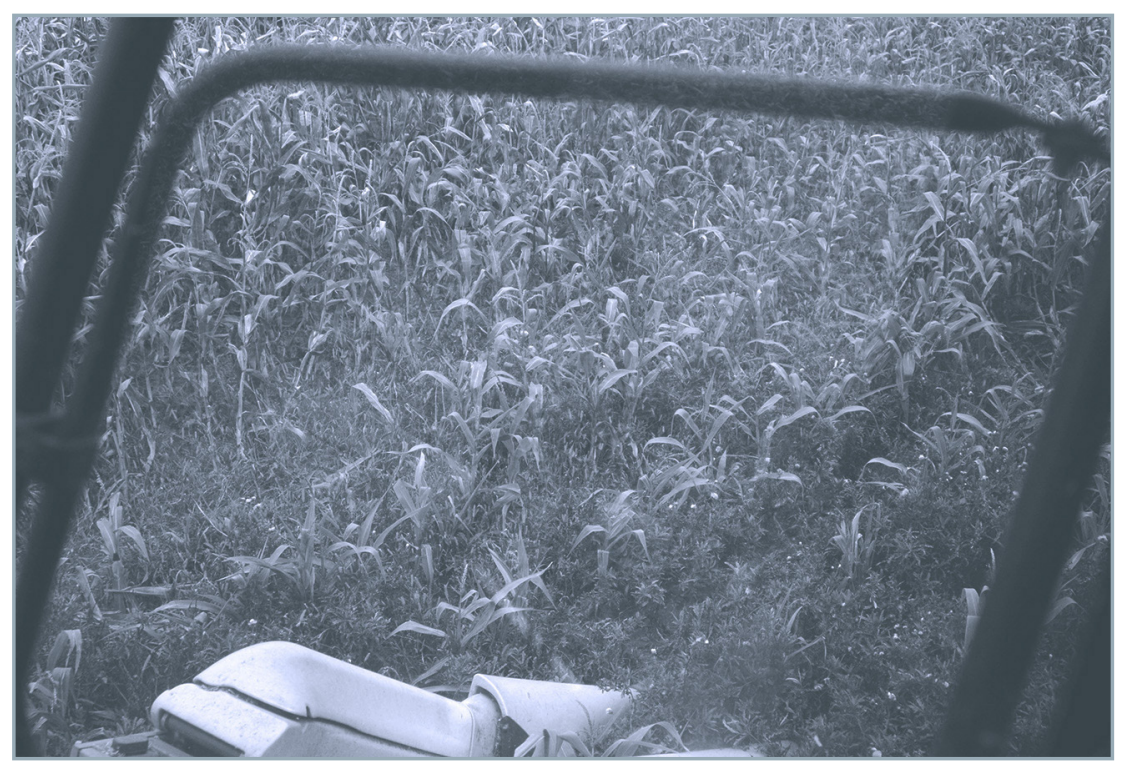

Figure 3 Variability of crop within the combine harvester header

the correlation of hand samples and yield monitor using all data across five growing seasons.
The analyses showed that the correlation of data is very strong, except for year 2009. When using the yield maps for an exact evaluation of field operations and their impact on yield, the absolute value at selected location needs to be determined as accurately as possible. The $t$-test showed at $p<0.05$ a significant difference among the two datasets in all years, except for 2010. In all other cases, the yield monitor estimated significantly different values of yield. Therefore, the errors in estimation were evaluated comparing the measured value by the yield monitor and the hand samples in pair, and the percent difference was calculated. The basic statistics of this difference (referred to as error) is given in Table 4, and the histogram is given in Figure 2.

The results show that the yield at individual locations of the field was estimated with an error up to 170 $\%$; however, the most frequent error was up to $25 \%$. This corresponds well with Colvin and Arslan (2002), who reported that high accuracy cannot be achieved in spot measurements; however, overall trend in yield can be determined. The extreme values of error could be caused by high variability of crop within the header of combine harvester (Figs 3, 4, 5). As the yield monitor determines the yield as an average of all width of the header and the samples represent smaller area, the difference in results might be expected.

Moreover, the calculated errors exceeded the typical yield monitor error, which is approximately $3.5 \%$ (Arslan and Colvin, 2002). Colvin and Arslan (2002) explained that this might be due to gradual speed changes, which caused the error to increase from about $3 \%$ to $5 \%$ in field tests, sudden changes in combine speed should be expected to increase errors even more. Similar results were achieved by Birrell et al. (1996). Furthermore, we think that the differences in absolute yield determined could be caused by losses during the harvest process as the yield monitor measures data when approaching the grain tank after the cutting, threshing and cleaning process.

\section{Conclusion}

High correlation (0.89) was obtained between the yield monitor data and hand samples; however, when looking at point measurements, the accuracy exceeded the declared 


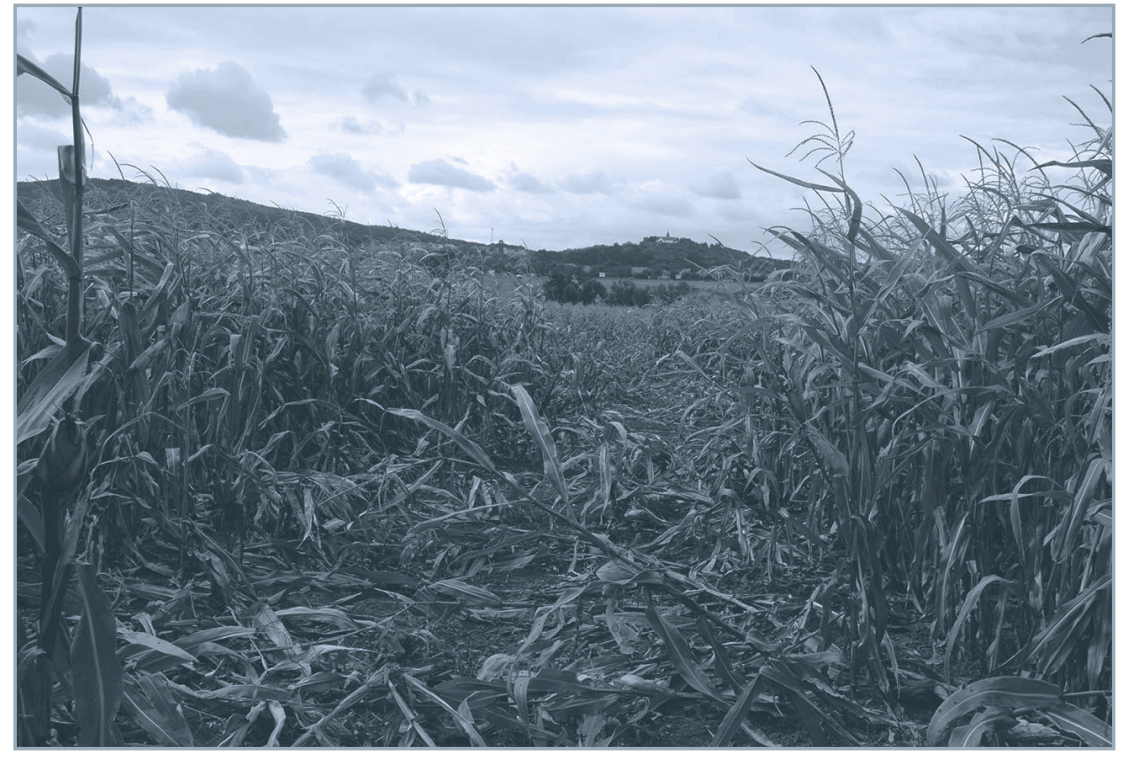

Figure 4

Maize crop damage at small areas of field

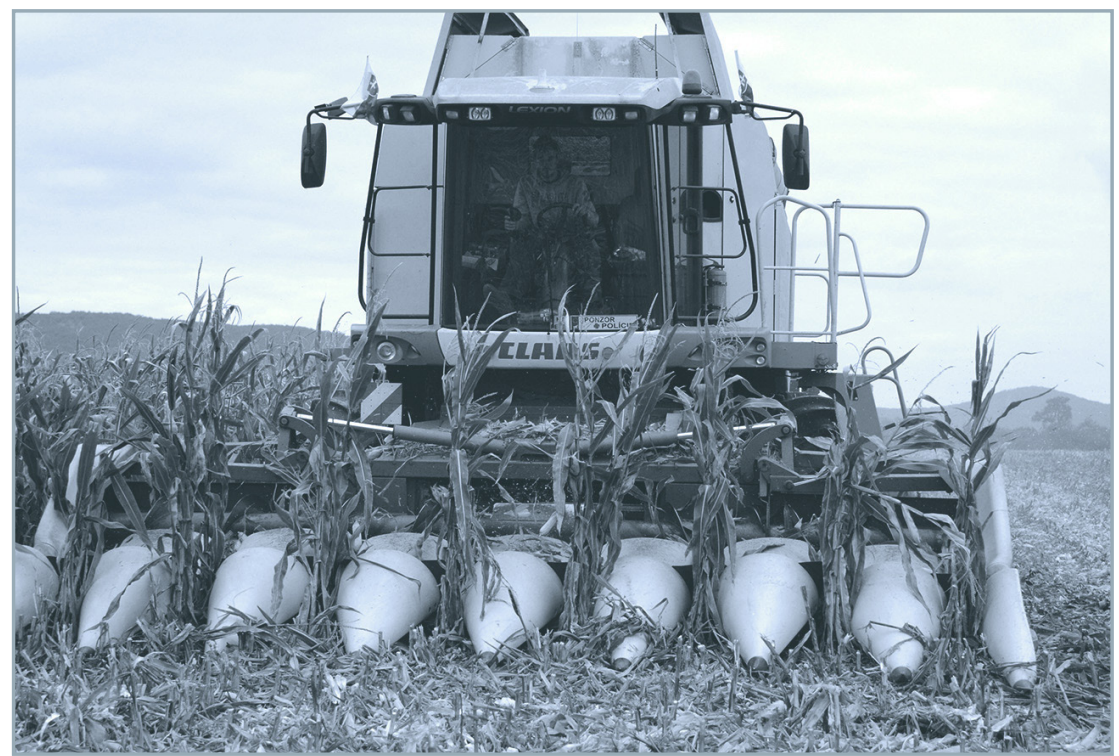

Figure 5

Combine harvester header

values by producer. Therefore, we do not recommend using the yield monitoring data obtained during the commercial use of combine harvester for evaluation of absolute yield at discrete locations; however, the yield trend at field was determined with sufficient accuracy.

\section{Acknowledgements}

This paper was prepared in the frame of the research project funded from the European Union under the title ITEPAg: Application of information technologies to increase the environmental and economic efficiency of the production agrosystem. ITMS 26220220014

\section{References}

ADAMCHUK, V. et al. 2004. EC04-704 Precision agriculture: Listening to the story told by yield maps. Historical Materials from University of Nebraska - Lincoln Extension. Paper 710. [online]. [Retrieved 2012-06-19]. Retrieved from: http://digitalcommons.unl. edu/

ARSLAN, S. - COLVIN, T.S. 2002a. An evaluation of the response of yield monitors and combines to varying yields. In Precision Agriculture, vol. 3, 2002, pp. 107-122.

AUERNHAMMER, H. - DEMMEL, M. - MUHR, K. - ROTTMEIER, J. - WILD, K. 1993. Yield measurements on combine harvesters. ASAE Paper no. 93-1506. St. Joseph, MI : ASAE.
BIRREL, S. J. - SUDDUTH, K. A. - BORGELT, S. C. 1996. Comparison of sensors and techniques for crop yield mapping. In Computers and Electronics in Agriculture, vol. 14, 1996, pp. 215-223.

BLACKMOORE, S. 2003. The role of yield maps in precision farming. [PhD thesis by papers]. Silsoe : Cranfield University, 2003.

BURKS, T. F. - SHEARER, S. A. - FULTON, J. P. - SOBOLIK, C. J. 2002. Effects of timevarying inflow rates on combine yield monitor accuracy. In Applied Engineering in Agriculture, vol. 20, 2002, no. 3, pp. 269-275.

COLVIN, T. S. - ARSLAN, S. 2002. Yield monitor accuracy. Site Specific Management Guidelines, 2002.

GALAMBOŠOVÁ, J. - GODWIN, R. J. 2012. Elements of precision agriculture. Nitra : SUA, 2012. ISBN978-80-552-0951-7.

INGELI, M. - RATAJ, V. - GALAMBOŠOVÁ, J. - MACÁK, M. - MESÁROŠ, L. 2013. Processing and interpretation of datas obtained from yield monitoring system. In Trends in Agricultural Engineering 2013. Prague : Czech University of Life Sciences Prague, 2013. pp. 277-281.

MOORE, M. 1997. An investigation into the accuracy of yield maps and their subsequent use in crop management. [PhD thesis]. Silsoe : Cranfield University, 1997. STOTT, B. L. -BORGELT, S. C. -SUDDUTH, K. A. 1993. Yield determination using an instrumented Claas combine. ASAE Paper no. 931507. St. Joseph, MI : ASAE, 1993.

맘 